\title{
Eye injuries from assault with chemicals
}

\author{
John D L Beare
}

\begin{abstract}
Sixty four patients with eye injuries resulting from assault with chemicals were reviewed. In 17 eyes of 16 patients there was total corneal epithelial loss with varying degrees of limbal ischaemia. Nine eyes were effectively blinded and two eyes suffered less severe but permanent impairment of vision.
\end{abstract}

Direct contact of noxious chemicals with the eye can cause severe eye injuries. Alkalis are particularly harmful..$^{1-10}$ We have seen a marked increase in the number of patients presenting with eye injuries resulting from assault with chemicals over the past six years. ${ }^{11}$ This trend has also been noted at other hospitals in London. ${ }^{12}$ Only one case was seen in 1984, increasing to three cases in 1985,15 cases in 1986, 37 cases in 1987, and 40 cases in 1988. The total fell again to 15 cases in 1989 (Fig. 1). The 15 assault cases seen in 1989 represented $8 \%$ of a total figure of 187 cases of chemical eye injury from all causes seen during that year. During the six-year period the total number of new patients seen per annum in the Accident and Emergency Department at the Western Ophthalmic Hospital has remained constant at about 8500 . Figures supplied by the Metropolitan Police Office (personal communication, 1989) also show a gradual increase in the number of assaults involving a noxious substance in the Metropolitan District over the period 1980-1988 (Fig. 2).

\section{Patients and methods}

The Western Ophthalmic Hospital is a busy eye hospital in the West End of London with 20333 patients seen in the Accident and Emergency department, and 29853 patients seen in the

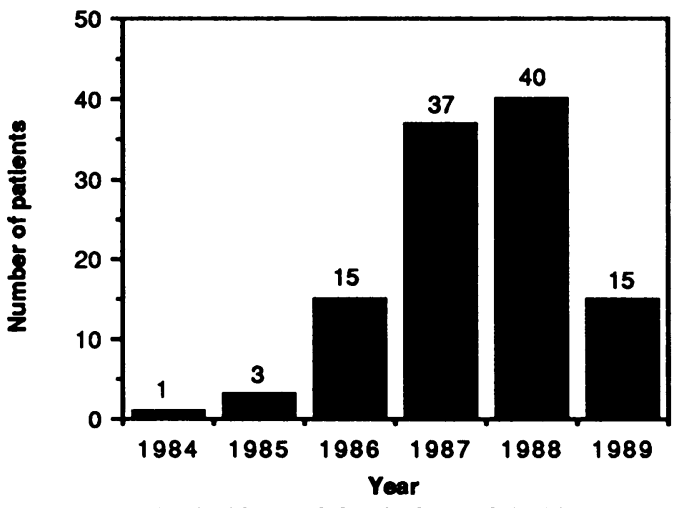

Figure 1: Rising incidence of chemical assault incidents involving the eyes 1984-9. outpatient department over the 12 month period January-December 1988. The hospital is situated on the edge of Paddington, a mainly residential area containing many different ethnic groups.

Diagnostic information on all new patients presenting to the Accident and Emergency Department over the past six years was retrieved from the booking-in ledgers. Information was obtained from the case notes of 64 patients seen between 1 January 1984 and 31 March 1988. Forty-four different parameters including the presenting ocular features, the circumstances of assault, and the severity of eye injury were recorded where possible. Twenty-six patients were seen personally by the author at presentation, while information on the presenting features of the remaining 38 patients was obtained retrospectively from the case notes.

Fifty four $(85 \%)$ of the 64 patients were eventually reviewed by the author. Minimum follow-up time on these patients was nine months after injury.

\section{Results}

VICTIMS

Of the 64 patients 55 were male and 9 female ( $86 \% \mathrm{M}: 14 \% \mathrm{~F}$ ). Their average age was 32 years (range 16-64). Approximately $10 \%$ of the victims were unemployed, $10 \%$ were students, $10 \%$ were visitors from overseas, and the remaining $70 \%$ were in full time employment apart from one housewife. The victims' occupations included a merchant banker, an electronics engineer, a computer programmer, a hospital pharmacist, and a chef.

Alcohol. At least 10 patients had been drinking heavily shortly before the assault. This was

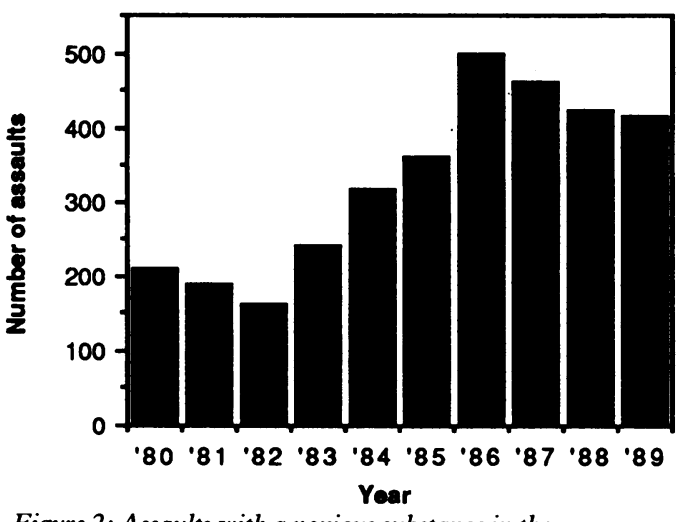

Figure 2: Assaults with a noxious substance in the Metropolitan Police District 1980-9. 
particularly common in the more severely injured patients, whose inebriated state may have contributed both to their being selected as victims and also to the delay in washing out their eyes or seeking attention.

Time of injury. Injuries occurred particularly during the latter half of the year, with $73 \%$ of the 64 cases occurring during the four-months August-November during the $41 / 2$-year period. This appears to have been largely due to two clusters of cases in August 1986 (six cases) and August 1987 (15 cases) which occurred at the Notting Hill carnival. The carnival is an annual event attracting up to one million people which takes place in the streets of Notting Hill over a three-day period in August of each year. This trend has been less marked in 1988 with a more even spread of cases over the year, and indeed only three ocular chemical burns due to assault at the carnival were seen in August 1988. Assaults were also more common in the evening, at weekends, or on public holidays.

Place. Forty seven assaults occurred in the street. Four patients were assaulted in an underground station, four while waiting at a bus stop, three patients were attacked in a public house, and two were assaulted in their homes. Details were not available on the remaining four patients.

Other injuries. Injuries other than to the eye were uncommon, though one man was stabbed in the abdomen, requiring laparotomy for a perforation of the small bowel. Significant facial and lid skin burns occurred in six cases, though there were no cases of serious facial or lid skin necrosis. Two patients reported coughing, but no patients had any acute respiratory problems due to inhalation.

Symptoms. Intense stinging and pain in the eyes were the usual symptoms immediately after being sprayed.

Attackers. Only one victim (a heroin pusher) actually knew his attacker. The assailants were most frequently gangs of youths, from early teenage to twenties in age, numbering up to 12 persons, and were male in every case.

Method. One patient was assaulted by several teenagers on bicycles who mounted the pavement in order to attack him.

A liquid was sprayed or thrown in most cases. A Jif Lemon ${ }^{12}$ was employed in four cases, an aerosol in five cases (probably containing a lacrimator such as Mace), and a child's water pistol was used in one case. In one case a white foam was sprayed from an aerosol.

Motive. The motive for the attack was usually unknown, though robbery occurred in $10 \%$ of cases. Most attacks were completely unprovoked and unexpected. Racial bias was a likely precipitant in several cases.

Chemical agents used in assault. The chemical agent used was usually not known, but six patients reported smelling ammonia shortly after the injury.

\section{INJURIES}

Thirty seven cases $(58 \%)$ of eye injuries were unilateral, and 27 (42\%) bilateral, making 91 eyes in total.
Irrigation. The time interval between injury and first irrigation ranged from 5 seconds to 12 hours. Several patients were inebriated by alcohol at the time of injury and did not seek medical attention until the following day. Irrigation was often performed on three separate occasions - first with tap water by the patient, secondly in the accident and emergency department of one of several large local general hospitals to which the patient was first referred, and finally at the Western Ophthalmic Hospital. Irrigation at the referring hospital was usually with normal saline, and a universal buffer solution (potassium dihydrogen orthophosphate 70 $\mathrm{g}$, sodium phosphate $B P 180 \mathrm{~g}$, distilled water to 1 litre) was used in all cases at the Western Ophthalmic Hospital.

Conjunctival sac $p H$. Universal indicator paper was used to test the conjunctival sac $\mathrm{pH}$ on the patient's arrival and was alkaline in 46 cases $(51 \%)$, with a $\mathrm{pH}$ range of $7 \cdot 0-9 \cdot 0$, neutral in four cases (4\%), acidic in one case (1\%), and was unrecorded in the remaining 40 cases $(44 \%)$ (total 91 eyes).

Initial classification of severity of injuries. The severity of injury was assessed according to Roper-Hall's ${ }^{1314}$ grading system. The majority of injuries $(73 \%$ were minimal (grade I). However, in $25 \%$ patients $(16 / 64)$ or $19 \%$ of injured eyes (17/91) there was total loss of corneal epithelium with varying degrees of limbal ischaemia. There was $180-360^{\circ}$ limbal ischaemia in nine eyes (grade 4), $90-180^{\circ}$ in two eyes (grade 3), and $<90^{\circ}$ in six eyes (grade 2) (Table I).

The degree of limbal ischaemia was often difficult to assess at first owing to gross chemosis and intraconjunctival and subconjunctival haemorrhage. Marked corneal stromal oedema was seen in all grade 3 and 4 injuries. A dilated pupil with large amounts of iris derived pigment on the corneal endothelium was indicative of very severe injury. Acute anterior capsular lens opacities, resembling Glaukomflecken were noted within two days of injury in the nine most severely injured eyes, reflecting chemical damage to the anterior lens capsule. A hypopyon was seen on the second day after injury in four eyes.

IOP. A raised intraocular pressure (IOP) was noted in four eyes at presentation, in patients who all had severe injuries. (Actual IOP values were 40,28 , and $28 \mathrm{mmHg}$ on day 1 , and $28 \mathrm{mmHg}$ on day 3 by Goldmann applanation tonometry.) Measurement of ocular pressure at presentation was often difficult owing to lid swelling and profuse watering and discomfort. This may explain why there were few early recordings of ocular pressure in the more severe injuries, despite evidence that such measurement is important. ${ }^{15} 16$ The incidence of raised IOP in grade 3 and 4 injuries is thus likely to have been an underestimate.

TABLE I Grading of severity of injuries at presentation

\begin{tabular}{lll}
\hline Grade & No of patients $(n=64)$ & Eyes affected $(n=91)$ \\
\hline 1 & $48(73 \%)$ & $74(81 \%)$ \\
2 & $6(9 \%)$ & $6(7 \%)$ \\
3 & $2(3 \%)$ & $2(2 \%)$ \\
4 & $8(15 \%)$ & $9(10 \%)$ \\
\hline
\end{tabular}


One patient with severe bilateral injuries had persistent ocular hypotony, first noted on day 4 and most likely due to ciliary body damage. Only one patient developed late secondary glaucoma. However, since corneal vascularisation and scarring caused problems with applanation tonometry, this may again be an undęrestimate.

\section{ADMISSION POLICY}

Thirty one patients (48\%) were admitted to hospital and $33(52 \%)$ treated as outpatients according to the severity of eye injury. The inpatient stay was an average 3.3 days, range 1-14 days. Outpatient visits were an average of $5 \cdot 3$ attendances per patient, with a range of $1-50$ outpatient attendances. The period of outpatient follow-up ranged from one day to 4 years.

TREATMENT

The patients were reviewed regularly as dictated by the severity of their injuries, though at no fixed time intervals. They were discharged after the first visit if the injury was very mild - for example, superficial punctate corneal erosions or mild conjunctival epithelial loss only.

Grade 1. The mildest injuries with punctate corneal epithelial erosions or with minimal corneal epithelial loss were treated with topical antibiotics (chloramphenicol) and mydriatics (cyclopentolate) alone.

Grades 2-4. All patients with more serious injuries (grades 2-4) were treated with ascorbate drops, ${ }^{17-19}$ initially hourly then usually reducing to two-hourly after three days. Ascorbate drops were continued until the corneal epithelium had healed. All patients were also given chloramphenicol drops initially two-hourly, and a mydriatic, usually atropine $1 \%$ drops in the more severe injuries, and cyclopentolate $1 \%$ in milder injuries. Topical steroid drops were given for all grade 2-4 injuries, usually dexamethasone hourly initially for the more severe injuries. Topical steroid treatment was continued for several weeks in the more severe cases, and no attempt was made to reduce or stop steroid treatment after one week. Despite this policy there was only one case of corneal perforation.

No patients were treated with autohaemotherapy, paracentesis, or other emergency surgical procedures which have been suggested as means of limiting progressive chemical damage.

The patients were under the care of several different doctors, and there was no strict treatment protocol. However, management was essentially the same in all cases as outlined above, with only minor variations in treatment.

Cost of treatment. The approximate total cost of treating all 64 patients based on an inpatient figure of $£ 200 /$ day and outpatient figure of $£ 35 /$ visit at 1988 prices was $£ 500$ per patient.

\section{CLINICAL COURSE AND OUTCOME}

Visual. The corneal epithelium rapidly healed in one to three days in the 47 patients $(73 \%)$ with grade 1 injuries. Twenty seven of these patients were reviewed on one occasion at periods ranging from four to 18 months after the original injury.
TABLE II Visual outcome in 16 most severely injured patients (with total corneal epithelial loss)

\begin{tabular}{|c|c|c|c|}
\hline Patient & Acuity & $\begin{array}{l}\text { Follow-up } \\
\text { (months) }\end{array}$ & Outcome \\
\hline \multicolumn{4}{|c|}{ Grade 4 (severe) } \\
\hline 1 & $\mathrm{CF}$ & 36 months & $\begin{array}{l}\text { LO, penetrating graft, recurrent } \\
\text { epithelial breakdown }\end{array}$ \\
\hline 2 & CF & 27 & $\begin{array}{l}\text { LO, heavily vascularised cornea, } \\
\text { ptosis }\end{array}$ \\
\hline $\begin{array}{l}3 \\
4\end{array}$ & $\begin{array}{l}\text { HM } \\
\text { PL, PL }\end{array}$ & $\begin{array}{l}16 \\
18\end{array}$ & $\begin{array}{l}\text { LO, secondary glaucoma, ptosis } \\
\text { LOs, persistent corneal epithelial } \\
\text { defects, severe hypotony, } \\
\text { depression }\end{array}$ \\
\hline 5 & PL & 12 & LO, depression \\
\hline 6 & PL & 12 & $\begin{array}{l}\text { LO, Staph aureus keratitis at } 4 \\
\text { weeks }\end{array}$ \\
\hline 7 & HM & 12 & $\begin{array}{l}\text { LO, Hypopyon on day } 1 \text {, } \\
\text { bacterial keratitis at } 32 \text { days, } \\
\text { eviscerated at } 5 \text { weeks }\end{array}$ \\
\hline 8 & HM & 1 day $\star$ & $\begin{array}{l}\text { Took own discharge from } \\
\text { hospital, hysterical }\end{array}$ \\
\hline \multicolumn{4}{|r|}{ Mospital, insterical } \\
\hline & $6 / 12$ & 12 & $\begin{array}{l}\text { LO, } 2 \text { mm ptosis, superior } \\
\text { pannus down to visual axis }\end{array}$ \\
\hline $\begin{array}{l}10 \\
\text { Grade } 2\end{array}$ & $6 / 7 \cdot 5$ & 8 & Superior pannus \\
\hline $\begin{array}{l}11 \\
12\end{array}$ & $\begin{array}{l}6 / 5 \\
6 / 9\end{array}$ & $\begin{array}{l}12 \\
12\end{array}$ & $\begin{array}{l}\text { No sequelae } \\
\text { Inferior pannus and corneal } \\
\text { scarring }\end{array}$ \\
\hline $\begin{array}{l}13 \\
14 \\
15 \\
16\end{array}$ & $\begin{array}{l}6 / 12 \\
6 / 4 \\
6 / 7 \cdot 5 \\
6 / 4\end{array}$ & $\begin{array}{l}1 \text { day* } \\
8 \text { days } \\
12\end{array}$ & $\begin{array}{l}\text { Foreign visitor, returned home } \\
\text { Inferior corneal scarring } \\
\text { Lost to follow-up } \\
\text { Minimal inferior corneal scarring }\end{array}$ \\
\hline
\end{tabular}

$\mathrm{PL}=$ perception of light. $\mathrm{HM}=$ hand movements. $\mathrm{CF}=$ counting fingers. $\mathrm{LO}=$ acute lens opacities present. ${ }^{\star}$ Short follow-up.

None had any residual eye symptoms, though two patients had mild superficial inferior corneal scarring.

Three out of six patients with grade 2 injuries had superficial inferior corneal scarring but were asymptomatic after a few weeks, with subjectively normal vision at follow-up on average 12 months later (see Table II). However, two of the six patients were lost to follow-up at one and 12 days. In one West Indian patient with a grade 2 injury ischaemic damage to the inferior limbus and presumably to bulbar conjunctival melanocytes caused local loss of conjunctival racial melanosis adjacent to the limbus. The two patients (3\%) with grade 3 injuries suffered a moderate permanent reduction of vision with marked corneal vascularisation. The eight most severely injured patients (15\%) had devastating grade 4 injuries, with gross corneal scarring and vascularisation, and permanently severely reduced vision, which was bilateral in one case (Fig 3).

Delayed epithelial healing. In grade 1 injuries the corneal epithelium was usually intact after four days even when there was subtotal corneal epithelial loss. Corneal epithelial healing was similarly only slightly retarded in grade 2 injuries. However, impaired corneal epithelial healing was a frequent problem in grades 3 and 4 injuries. The corneal epithelium eventually covered the denuded and damaged cornea after 11-53 days in six of these patients, In five eyes of four patients persistent epithelial defects were associated with stromal lysis and thinning.

Infective keratitis. There were two cases of infective keratitis, both caused by Staphylococcus aureus. Both occurred four weeks after the chemical injury in patients with persistent corneal epithelial defects and progressed to perforation of the globe in one case. This case occurred seven days after the insertion of a 'bandage' soft contact lens which had been 


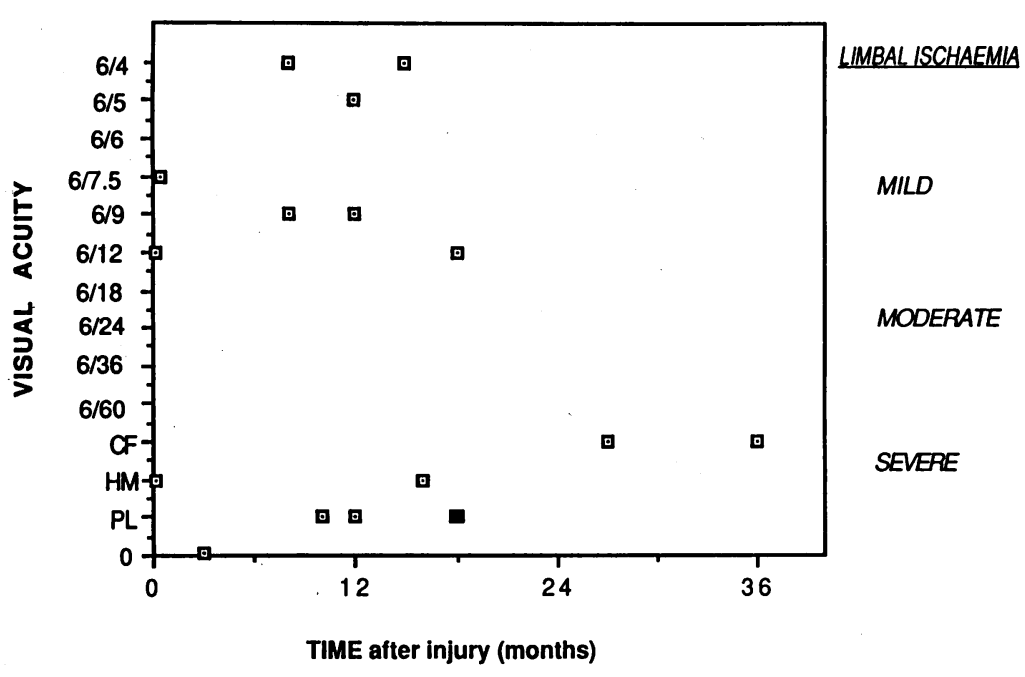

Figure 3: Visual acuity follow-up on 17 eyes with total corneal epithelial loss. $\square$ Represents both eyes of one patient.

inserted in order to encourage corneal re-epithelialisation.

Corneal graft. Only one of the 64 patients underwent corneal grafting, performed at 20 months after injury. After an initial reasonable visual result $(6 / 18$ corrected vision) the continuous 10/0 nylon corneal suture became loose and had to be removed. Removal of graft sutures led to recurrent corneal epithelial breakdown, necessitating continuous wear of a bandage soft contact lens and a disappointing visual result.

Lid complications and symblepharon. A mild 1-2 mm ptosis was seen in six patients with severe injuries, which persisted for six months or more. In cases with ptosis significant upper tarsal conjunctival scarring was present, with slight inward buckling of the tarsal plate in three patients. However, there were no cases of actual upper lid entropion.

Surprisingly, we saw no cases of significant symblepharon among the 64 patients. This may be a reflection of both the severity of burn and also possibly the types of chemicals that were used for assault, since symblepharon is well known to be a common complication of severe lime burns.

Psychological problems. These were common in the aftermath of injury. Depression occurred often in the more severely injured patients, where the final result was frequently an unsightly, red, uncomfortable, and almost blind eye. One patient had severe bilateral injuries and is now registered as blind. He has been severely depressed and has tried to commit suicide on several occasions.

\section{Discussion}

Violent crime in London rose by a quarter between 1986 and $1987 . .^{20}$ The incidence of chemical eye injuries ${ }^{11} 12$ due to assault has risen in parallel, though the sudden upsurge seen in 1987-8 seems to have temporarily abated.

The only other recently published large series of ocular alkali burns resulting mainly from assault was a retrospective study from the USA by Klein and Lobes in $1984,{ }^{21}$ which contrasts sharply with the present series. Of the 52 patients whose notes contained sufficient information, assault was the cause in at least 35 cases. The assailants were all women where described; $22 \%$ of assaults took place in the home, and $44 \%$ of the victims were chronic alcoholics. There was a high proportion of very severe burns, with $39 \%$ of 100 eyes classified as very severely damaged under the Hughes classification, compared with only $12 \%$ (grades 3 and 4 combined) in the current series. In the American series $58 \%$ of eyes had a final visual acuity of less than $20 / 200$ and a high perforation rate of 13 out of 100 eyes; $67 \%$ received topical steroids, though none were treated with ascorbate or citrate drops. ${ }^{17}$ The very high rate of symblepharon $(29 \%)$, and secondary glaucoma $(18 \%)$ in that series is a further indication that patients were more severely injured.

\section{CONCLUSIONS}

The nine most severely injured patients in the present series fared badly, though only one eye became perforated. The low perforation rate is no doubt a reflection of milder injury and it is not possible to speculate usefully on whether the additional use of topical ascorbate may have in any way contributed to the better outcome. The dismal visual results after severe alkali burns of the eye have been previously emphasised by Pfister: 'The best result that can be obtained in an eye after a severe alkali burn is a totally vascularised and scarred cornea that has not undergone ulceration and in which glaucoma has not developed.'

The most important conclusions to be drawn from this study are that severe chemical burns of the eye still fare badly despite the introduction of ascorbate and steroid treatment, and that such patients are expensive to treat. Effort should therefore be directed towards the prevention of such injuries in the future. Suggested means by which this could be achieved are:

(1) Identification of the chemical weapons used in assault cases.

(2) Limiting availability. The banning of over the counter sales of noxious substances is a possible option, as has been previously suggested. ${ }^{21}$ The continued sale of ammonia to persons under 18 demands particular consideration. Safer but no less efficacious household cleaning agents are widely available.

(3) Education. The extreme urgency of effective and prolonged irrigation with tapwater after any chemical contact with the eye should be stressed to the public, ambulance, first-aid, and accident and emergency staff. All medical, nursing, and paramedical staff should receive detailed instruction on irrigation technique, including eversion of the eyelids. ${ }^{22}$

(4) Treatment. Further research is needed into means by which the poor visual prognosis for severe chemical eye injuries can be improved.

1 Duke-Elder S. A system of ophthalmology. London: Kimpton, 1972; 14 (2): 1011-207.

2 Grant WM. Toxicology of the eye. Springfield: Thomas, 1986 3rd ed.

Wright P. the chemically injured eye. Trans Ophthalmol Soc UK 1982; 102: 85-7.

4 Hughes WF Jr. Alkali burns of the eye: I. Review of the literature and summary of present knowledge. Arch Ophthalmol 1946; 35: 423-49. 
5 Hughes WF Jr. Alkali burns of the eye: II. Clinical and pathologic course. Arch Ophthalmol 1946; 36: 189-214.

6 McCulley JP. Chemical Injuries. In: Smolin G, Thoft RA, eds The cornea: scientific foundations and clinical practice. Boston, Toronto: Little, Brown, 1983; chapter 14: 422-35.

7 Nelson JD, Kopietz LA. Chemical injuries to the eyes: emergency, intermediate, and long term care. Postgrad Med 1987; 81: $62-75$.

8 Pfister RR. Chemical injuries of the eye. Ophthalmology 1983; 90: 1246-53.

9 Pfister RR, Koski J. Alkali burns of the eye: pathophysiology and treatment. South Med F 1982; 75: 417-22.

10 Pereleux A. Chemical burns of the eye. Bull Soc Belge Ophthalmol 1986; 217: 35-43.

11 Beare JD, Wilson RS, Marsh RJ. Ammonia burns of the eye: an old weapon in new hands. BrMed $\mathcal{F} 1988 ; 296: 590$.

12 Morgan SI. Chemical burns of the eye: causes and management. Br 7 Ophthalmol 1987; 71; 854-7.

13 Roper-Hall MJ. Thermal and chemical burns. Trans Ophthalmol Soc UK 1965; 85: 631-46.

14 Eagling EM, Roper-Hall MJ. Eye Injuries: an illustrated guide. London: Butterworths, 1986.
15 Paterson CA, Pfister RR. Intraocular pressure changes after alkali burns. Arch Ophthalmol 1974; 91: 211-8.

16 Chiang TS, Moorman LR, Thomas RP. Ocular hypertensive response following acid and alkali burns in rabbits. Invest Ophthalmol Vis Sci 1971; 10: 270-3.

17 Pfister RR, Paterson CA, Hayes SA. Topical ascorbate decreases the incidence of corneal ulceration in alkali burned corneas. Invest Ophthalmol Vis Sci 1978; 17: 1019-24.

18 Pfister RR, Paterson CA. Ascorbic acid in the treatment of alkali burns of the eye. Ophthalmology 1980;87: 1050-7.

19 Levinson RA, Paterson CA, Pfister RR. Ascorbic acid prevents corneal ulceration and perforation following experimental alkali burns. Invest Ophthalmol Vis Sci 1976; 15: 986-93.

20 Kirby T Crime being forced onto the streets. Independent 16 December 1988: 4 (cols 1-5).

21 Klein R, Lobes LA. Ocular alkali burns in a large urban area. Ann Ophthalmol 1976; 8: 1185-9.

22 Beare JD. Management of chemical burns of the eye. In: Murray V, ed. Major chemical disasters - medical aspects of management. London: Royal Society of Medicine Services International Congress and Symposium Series No. 155 1990: 151-61 (in press).

号 